\title{
The Metaphor of Dialogue: Philosophical Conceptualization and Implementation to Social and Learning Practice
}

\author{
Oleksandr Polishchuk \\ Doctor of Philosophical Sciences, Associated Professor, Khmelnytsky Humanities \\ and Pedagogic Academy (Khmelnytsky, Ukraine) \\ E-mail: prokurator2007@ukr.net \\ ORCID: 0000-0002-9838-7105
}

\section{Galyna Buchkivska}

PhD, Associated Professor, Ternopil Volodymyr Hnatyuk National Pedagogical University (Ternopil, Ukraine)

E-mail: buchkivska1810@gmail.com

ORCID: 0000-0002-4836-8280

\section{Liudmyla Pavlishena}

PhD, Associated Professor, Khmelnytsky Humanities and Pedagogic Academy

(Khmelnytsky, Ukraine)

E-mail: pavlishena.76@ukr.net

ORCID: 0000-0003-1807-588X

An article is devoted to philosophical and conceptual analysis of the notion of dialogue. Potentialities of dialogue in education and personality formation are explored. The conclusion about the crucial role of the implementation of dialogue in the field of education and culture has been made on base of the interpretation of the contemporary crisis of culture as a crisis of the communication system. It is proved that the main determinants of the concept of dialogue are able to organize effective communication in solving the problems of modern social culture.

Keywords: dialogue, communication, tolerance, mobility, education, globalization, culture.

Received 09 June 2017; accepted 19 September 2017

Philosophy and Cosmology, Volume 20, 2018: 120-127

DOI: $10.29202 /$ phil-cosm/20/11

(C) Polishchuk, Oleksandr, 2018

(C) Buchkivska, Galyna, 2018

(C) Pavlishena, Liudmyla, 2018 


\section{Introduction}

The concept of dialogue has a long tradition in philosophy and culture. The ability to communicate is fundamental to the existence of human, society, and culture. The current situation brings a special meaning and importance of the philosophical analysis of the phenomenon of dialogue. The huge growth of communication technologies has changed the status of modern society, the main attribute of the definition of which becomes information. The Information Society produces communication content of enormous intensity. Consciousness is involved in the information and communication flows of modern civilization, often against its own will or without of appropriate motivation. These processes are dangerous of disorientation, acute emotional reaction, the spectrum of which is wide ranging from apathy to aggression. Besides, an information and communication technologies create a space of virtual reality. It involves a qualitatively new type of interaction, the main determinants of which are anonymity and voyeurism, trolling and nomadism. In fact, this type of communication is opposed to the concept of dialogue. Moreover, these factors are disastrous for the consciousness, society, and culture. Network thinking, clip culture, information as a tool and means of influence give particular urgency to the problem of dialogue in the modern world.

Parity, responsibility and meaningfulness are the main dominants of dialogical communication. That is why it is customary to define the way of interaction of cultures in the civilized world precisely as a dialogue. However, dialogue is a communication of different subjects. However, the modern globalized world is increasingly unified. Differences in daily practice, tastes, evaluation criteria and values among representatives of various social and cultural communities are eroding. This unification of the socio-cultural space leads to radicalization of the reaction of the "dissenters", which is clearly seen in the revenge seeking of the ultra-right currents in Western Europe, in the idea of the "Russian world", or terrorism as well. A well-known manifesto of European philosophers about the need to keep traditional European values is nothing else than the principled position of refusing to dialogue. It is known that the only one way to end the conflict on a latent stage is a communication. A conscious exit from the communicative space is a frank confrontation with all the ensuing consequences. Therefore, dialogue in the modern world is a kind of strategy and tactic of the survival of mankind.

There is a clash of two opposing tendencies in terms of humanitarism in the modern world. On the one hand, there is the undoubted fact of dehumanization of the worldview foundations of modern society. Apathy, cynicism, consumerism determine the mood of the era. On the other hand, the humanization of the person is the main task of education. The founder of the concept of the noosphere Volodymyr Vernadsky stated this, and it is difficult to disagree with him. The dialectic of the concepts "society" and "education" is analogous to the relation of categories "real"/"ideal". Really, education is not confined to the present; it is actualized into the future, and is focused of some ideal, or pattern. The nature of this interaction between society and education is also, in fact, dialogical. The society produces a request, or a challenge, and education satisfies it on the basis of the meanings and values of culture.

Dialogue is also defined as communication of interested persons. Such interest, or involvement in activities, is a guarantee of its effectiveness and success. Indeed, the concept of dialogue does not involve passive participation. The mandatory components of the dialogue are activity, awareness and purposefulness. All these qualities are necessary for the formation of civil society as a genuine realization of the principles of democracy and social justice. 
Consequently, the problem or metaphor of dialogue is not only relevant in modern scientific and educational discourse, but also very productive for solving a whole spectrum of socio-cultural problems.

\section{Dialog as a Philosophical Concept}

Philosophical analysis of the phenomenon of dialogue reveals its significant sociocultural potential. The source of the philosophical category of dialogue takes in Antiquity. Eristic as a theory of argument with the emergence of philosophical discourse divided into sophistry and dialectics. These modes of dialogical interaction are distinguished by their target predetermined, or by the representation of the result. However, the idea of civil freedom allows existing different points of view, different interests and values. Thus, the system of education of Antiquity is constructed: learning through fellowship, by Paideia and dialogue.

Cardinal changes in the content of the meaning of dialogue in education as the formation of the personality and its outlook occur in the Middle Ages. Thinking within the framework of religious doctrine projects the notion of absolute truth and the only one way to achieve it. Thus, scholasticism has formed the basic principles of didactics, using the principle of monologue. Another, dissenting in this type of discourse is a heretic, an apostate, or an enemy. It is natural that modernism in philosophy and German classics in particular, is marked by the return of the concept of the Other into the space of subjectivity. If we analyze the history of philosophy from Francis Bacon to Blaise Pascal, we find an abyss between the theory of knowledge (the theory of subjectivity) and social philosophy (the theory of society). This localization of the problem field is a consequence of the monologism of the Middle Ages. The absence, or demonization of the Other leads to the isolation of subjectivity, right up to Rene Descartes' radical doubt or the skepticism of David Hume. It turns out that the concept of the Other is necessary to substantiate the essence and existence of one's own subjectivity. This understanding of the Other's concept was transformed in Kantian philosophy into a dialectical system of higher intelligence, and the transcendental nature of the categorical imperative, according to which the Other is the goal of life activity, and not a means of realizing one's own interests. According to the philosophy of Johann Gottlieb Fichte, dialogism is revealed in the dialectic of the fundamentals of subjectivity. Fichte also makes a very decisive and productive step, defining the "meeting place" of subjectivities as the field of realization of freedom, or goal-oriented activity. This is the space of history and culture, personality and public, education and society.

A new horizon and trajectories of understanding of dialogue are developed by existentialism. Karl Jaspers unhesitatingly affirms that "human being is always being with the Other". Dialogue fulfills a constitutive role in relation to the human essence. Undoubtedly, this doom to sociality, self-identification through reflection in the mind of the Other, can be excruciating. It is very reasonably written by Jean-Paul Sartre. The Other makes not only a suffering, but a true panacea from fear and horror of being. Emmanuel Levinas wrote very deeply about the understanding of the Other as the goal of meaning. Thus, human existence acquires content and meaning through dialogue with the Other.

Postmodernism as a world view and as a characteristic of contemporary creates a different understanding of the Other and ways of dialogue with him. Gilles Deleuze connects the concept of the Other with the procedure of "interiorization the external", or the assimilation of historical and cultural experience. It is a procedure of the creation of a certain objectified spirit, polar to own subjectivity. The illustration of this phenomenon Deleuze calls "fold". This is a postmodern allusion of the classical principle of the bifurcation of the single. In 
the classical philosophical paradigm, this principle has ontological grounds and serves as the basis for the diversity of the world. This is the principle of pluralism of random and indeterminate constants in postmodernism. We note two fundamentally new tendencies of the contemporary: first, the openness and plasticity of consciousness under the influence of external factors. Second, the fragility of the general semiotic field and the absence of a clear reference. In such case, the need for productive dialogue only grows, becomes a necessary condition for the formation of self-sufficient subjectivity and a conscious social community.

Mikhail Bakhtin, Martin Buber and Vladymyr Bibler create a universal panorama of human activity based on principle of dialogism. The whole spectrum of human relationships, sphere of meaning and significance has a dialogical nature. In this aspiration to the Other, transcendence reveals itself as the realization and explication of the human essence.

There are some contemporary heuristic interpretations of dialogue paradigm. Morris V. Libby argues an attributive link between critical thinking and critical dialogue as a highly effective method of teaching [Libby, 2017]. According to some authors, the information society of future is necessarily involved in the logic of scientific interaction [Barth et al., 2017: 811-828]. Hence, the communication of the social community has reasons to regard as community learning through dialogue and communication. Ina Blau and Tamar ShamirInbal created re-designed flipped learning model in an academic course, according to which the role of co-creation and co-regulation in the educational process is substantially transformed [Blau \& Shamir-Inbal]. A contemporary Ukrainian researcher of this problem in relation to the sphere of education Olena Troyitska calls dialogue an integrator and constructor of cognitive, communicative and praxeological competences of Homo educandus (subjectivity, sociability, interculturality) [Troyitska, 2016].

Therefore, the theoretical and methodological basis for investigating the problem of dialogue gives us such determinants of its content.

1. Dialogue is a meaningful goal-oriented interaction of free-thinking subjects.

2. Lack of dialogue, the predominance of the monologic type of communication is detrimental to subjectivity and civil society as a whole.

3. Productive dialogue is possible only with the maximum acceptance of the interlocutor's position.

4. Dialogue as the most effective type of communication makes a basis for creating a semiotic field of history and culture.

5. Inclusion in the dialogue is revealed as transcendence, overcoming the realm of available being for the purpose of ascertaining and acquiring meaning.

6. The result of dialogical interaction is a significant transformation of consciousness and thinking of participants of the process.

All these factors give us grounds to assert that the metaphor of dialogue permeates the whole process of education. In addition, the most productive potentialities of dialogical interaction are revealed in the system of higher education. This is due to the academic freedom of the higher school and its proximity to scientific research.

\section{The Present and Future of Higher Education: From a National Monologue to a Global Dialogue}

The system of higher education in Ukraine, as in the whole world, is a complex system of communication. This multilevel complex of links includes social institutions and organizations, social communities and groups, social stereotypes, roles and individuals with their own existential experience. How does the concept of dialogue find its place in 
the complex communicative and synergistic construct of the higher education system? The answer lies in understanding of dialogue and communication as different types of discourse, different language games. This idea is substantiated at the series of contemporary researches [Bazaluk, 2015; Barth et al., 2017; Bosetti, 2011; Gonda, 2014; Krichevsky, 2017]. The purpose of communication is the translation of information, the transfer of knowledge. This discursive practice is based on the need to reproduce society. Such public, or objectified nature of communication uses a fully formalized information code. Indeed, formalization is absolutely necessary for scientific discourse. In view of its absence, science will lose its own specification.

On the other hand, the formalization inherent in scientific discourse leads to standardization and stereotyping of thinking. In the philosophy of science, this phenomenon is called a paradigm (Thomas Kun) or an episteme (Michel Foucault). The last one called this evolutionary process "thinning out speaking subjects". In the objectified communicative space of scientific discourse, that one will be heard, who will formalize the meaning and content of knowledge in an acceptable way. However, the ontogenesis of culture, like the existential experience of human, does not tolerate monotony. Scientific revolutions, insights in art, the events of personal experience are realized through the rupture of monotony and overcoming the stereotype. Dialogue is this existential act of breaking the continuity of ordinary, standard and formality. The event of dialogue is the overcoming of one's own subjectivity, the transcendence from knowledge (possession of information) to understanding (filling of information with personal value content).

Perfect philosophical analysis and illustration of this striking difference between communication and dialogue is offered by the famous semiotic philosopher Yuri Lotman. A type of communication, which content is in broadcasting of information, Lotman calls it spatial. This definition is justified by the fact that information changes the holder, the location of being, but it remains equivalent to itself. Another type of communication is close to the concept of dialogue, Lotman calls it temporary. Its essence is in a result of the transformation of information into knowledge (meaning), in qualitative changing the holder, the participant of the process. Spatial communication is superficial in content and operational in terms of functionality. Spatiality of communication is related to network thinking and clip culture. In addition, of course, it is demand by modern society and culture. Temporary communication is attributive to the understanding of culture as a space of explication of the spirit. This is the hierarchical structure of an axiological character. As an example of spatial communication, we may remember speaking with artificial intelligence, for example Siri. Alternatively, there is an interview with a student reading out some theses of the abstract without realizing the content and meaning of his work. This is the reproductive level of mastery of information. Temporary communication changes the worldview of the subject. The temporality in such key means a qualitative transformation, the formation of a new or the acquisition of integrity.

We will lead the following reflection to explain the importance of temporality in the dialogue. Language as a sign-symbolic system and speech as the transformation of ontological reality into a semiotic reality is essentially an operation of replacing a thing by its designation. Temporality reveals the way of being things, the modes of its existence, the causes and prerequisites for its presence and absence. The extension of the existence of a thing forms the structure of its meanings, or essence. A sign as a unit of speech represents a thing in the horizon of existence, that is, the explication of its essence. Therefore, speech is rightly called a way of manifestation, denotation and signification of reality. Spatial communication is a grasp of the integrity of the representant, or a sign, without reflecting and analyzing 
its essence. Temporary communication, or dialogical collaboration, reveals the dynamics of meaning in the dialectic of the diversity of arguments and the unity of meaning.

Of course, both types of communication are absolutely justified in their existence and use in the field of education. Therefore, dialogue, or temporary communication, has a form-building potential in the formation of personality. A spatial type of communication is effective in organizing micro-training, or design-thinking. These skills are particularly demand in connection with the intensity of civilizational processes. The combination of these communication strategies is very effective. After all, a modern specialist should have critical thinking, high level of efficiency and be easily trained.

The main criterion in characterizing of the education is a principle of competence. The first and basic element of it is knowledge. This is the reproductive level of information ownership, or the spatial type of communication. The subsequent components of the formation of competence (assessment of information, the establishment of its meaning, the detailing of the image or concept, introduction into practice) are possible only through temporary communication, or dialogue. We could to achieve a comprehension of information only through problematization of content. Concerning this assertion, we find an excellent justification of Mikhail Bakhtin: "Sense is an answer to a question" [Bakhtin, 1979: 363]. Therefore, it is possible to transform information or a sign into knowledge or meaning through dialogue, including internal dialogue.

However, do not underestimate the importance of the social environment, which produces higher education. The great theoretician of academic education and free university Wilhelm von Humboldt argued that the special atmosphere of interaction in the scientific research of scientists and students is able to form a "whole person". Dialogue of people interested in scientific creativity is most productive both to the point of view of socio-cultural progress and to the standpoint of personal growth.

However, it is exactly a dialogue, and not a monologic presentation of a formalized text, which essentially is a lecture. Passive consumption of information is not very productive in the educational process. For the analysis at the level of meaning it is necessary a problematization of content. Therefore, there is a remarkable practice among European university teachers to publish educational and methodological manuals for their courses. Preliminary acquaintance with the content of the academic discipline makes it possible to use the time of academic work more productively.

A decisive step in the intensification of intercultural ties in education is to consider the principle of mobility, actively introduced in the European space of higher education. Dialogue of representatives of different cultures and mentalities in a single field of scientific research creates the effect of a certain "stereoscopic vision" of the problem. This cooperation is very fruitful in many respects: scientific, educational, political, economic, and cultural. A long period of closed by ideology, monologic development of Ukrainian science and education is completed. Denys Svyrydenko justly states that "the problematic of mobility is becoming central to the researches of the modern social dynamics" [Svyrydenko, 2016: 104.]. Mobility in education certainly contributes to the process of globalization. The multicultural nature of modern civilization is dangerous because of the emergence of conflicts on the basis of misunderstanding.

Therefore, the problem of the dialogue at the educational space is especially urgent. The abstract formation of tolerance is impossible; the realization of this principle arises only in the collision with the Other. There is an opinion that the modern crisis of culture is a crisis of the communication system. The variety of information flows, the collision of interests, the inconsistency of value systems and methods of evaluation significantly reduce 
the effectiveness of communication. Only a productive dialogue can reduce the scale of the entropy of this information space. It is logical that education in this process can play a decisive role.

In addition, communication in the university environment is not limited to academic studies. According to the theory of "background expectations", immense importance in the development of information belongs to the environment, the environment in which there is interaction. The creative collective or community of the university is a medium of formal and informal communication, during which activation of the heuristic activity, development of skills of critical thinking and emotional intelligence takes place. All these qualities are necessary for a successful specialist, whose training is carried out by the higher education system.

\section{Conclusions}

The accentuation of the problem of dialogue in higher education is based on the recognition of the need for multiculturalism, the liminality of modernity in the context of globalization, the understanding of tolerance as the initial setting of communication, the approval of the horizontal logic of interpersonal relations, and the realization of the creative and heuristic potential of all participants in communicative interaction.

The involvement of dialogic practices in the system of education will not only increase the level of science and education, but also contribute to solving a whole range of problems of modern socioculture. All these properties of the dialogue can bring order and harmonize social relations in today's globalized world. Therefore, it is necessary to use the productive potential of dialogue in solving urgent problems of the education system and society as a whole.

\section{$\mathbb{E D}$ References}

Bakhtin, Mikhail. K Metodologii Gumanitarnykh Nauk. Estetika slovesnogo tvorchestva. Moskva: Iskusstvo, 1979: 361-373.

Barth, Matthias, Daniel J. Lang, Philip Luthardt and Ulli Vilsmaier. Mapping a sustainable future: Community learning in dialogue at the science-society interface. International Review of Education. Vol. 63, Issue 6, 2017: 811-828. DOI: 10.1007/s11159-017-9687-5

Bazaluk, Oleg. Postmodernism: Philosophy of Education. Future Human Image. Vol. 2 (5), 2015: 9-22.

Bazaluk, Oleg, Denys Svyrydenko, and Serhii Terepyshchyi. Structural-functional models of integration and reintegration of Ukrainian educational landscape. Naukovyi Visnyk Natsionalnoho Hirnychoho Universytetu, Issue 5, 2017: 163-168.

Blau, Ina and Tamar Shamir-Inbal. Re-designed flipped learning model in an academic course: The role of co-creation and co-regulation. In Computers \& Education. Vol. 115, 2017: 6981. DOI: 10.1016/ j.compedu.2017.07.014.

Boschetti, Fabio, Jennifer Price and Iain Walker. Myths of the future and scenario archetypes. Technological Forecasting and Social Change. Vol. 111, 2016: 76-85. DOI: 10.1016/j. techfore.2016.06.009

Bosetti, Giancarlo. Introduction: Addressing the politics of fear. The challenge posed by pluralism to Europe. Philosophy \& Social Criticism. Vol. 37, Issue 4, 2011: 371-382. DOI: 10.1177/0191453711400998

Cherepanova, Svitlana. The Subject of Culture within the Objective Scope of the Philosophy of Education. Future Human Image. Vol. 8, 2017: 30-40. 
Gonda, Mahadappa G. Role of Educational Institutions in Shaping the Future of Business and Society. Procedia Economics and Finance. Vol. 11, 2014: 635-641. DOI: 10.1016/S22125671(14)00229-9

Kieliszek, Zdzislav. The Timeliness of Kant's Vision of Copyright. Studia Warminskie. 53, 2016: 9-23.

Krichevsky, Sergey. A Management Concept of the Technosphere's Evolution. Philosophy and Cosmology. Vol. 18, 2017: 153-164.

Libby, Morris V. Moving beyond Critical Thinking to Critical Dialogue. Innovative Higher Education. Vol. 42, Issue 5-6, 2017: 377-378. DOI: 10.1007/s10755-017-9413-z

Svyrydenko, Denys. Mobility Turn in Contemporary Society as an Educational Challenge. Future Human Image. Vol. 3 (6), 2016: 102-108.

Troyitska, Olga. Dialoh i tolerantnist u kulturno-osvitnomu prostori vyshchoyi shkoly. Melitopol: Vyd-vo MDPU imeni B. Khmelnytskoho, 2016. 